\title{
IL-36y Augments Host Defense and Immune Responses in Human Female Reproductive Tract Epithelial Cells
}

\section{Sean M. Winkle, Andrea L. Throop and Melissa M. Herbst-Kralovetz* \\ Department of Basic Medical Sciences, College of Medicine-Phoenix, University of Arizona, Phoenix, AZ, USA}

IL-36y is a proinflamatory cytokine which belongs to the IL-1 family of cytokines. It is expressed in the skin and by epithelial cells (ECs) lining lung and gut tissue. We used human 3-D organotypic cells, that recapitulate either in vivo human vaginal or cervical tissue, to explore the possible role of IL-36y in host defense against pathogens in the human female reproductive tract (FRT). EC were exposed to compounds derived from virus or bacterial sources and induction and regulation of IL-36 $\gamma$ and its receptor was determined. Polyinosinic-polycytidylic acid (poly I:C), flagellin, and synthetic lipoprotein

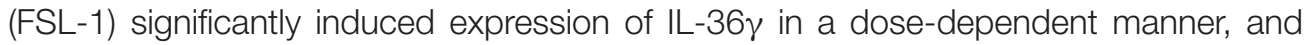
appeared to be TLR-dependent. Recombinant IL-36y treatment resulted in selfamplification of IL-36y and its receptor (IL-36R) via increased gene expression, and promoted other inflammatory signaling pathways. This is the first report to demonstrate that the IL-36 receptor and IL-36y are present in the human FRT EC and that they are differentially induced by microbial products at this site. We conclude that IL-36y is a driver for epithelial and immune activation following microbial insult and, as such, may play a critical role in host defense in the FRT.

\footnotetext{
Keywords: IL-1 family, IL-36y, human epithelial cells, antimicrobial peptides, innate immunity, IL-36 receptor, microbial products, inflammatory mediators
}

\section{INTRODUCTION}

The epithelium of the human FRT plays host to a wide variety of commensal bacteria and acts as a first responder to invading microbes and changes in the microbial milieu. The human FRT can be divided into two distinct regions that differ in cellular structure and function. The lower FRT epithelium is composed of the vagina and ectocervix and is lined with a stratified squamous epithelium built to resist physical and mechanical stress. The upper FRT epithelium is made up of a single layer of columnar EC and includes the endocervix, endometrium, fallopian tubes, and the uterus (Horne et al., 2008). Site-specific differences in the magnitude and pattern of immune response have been investigated in the vagina and endocervix (Quayle, 2002; Pudney et al., 2005; Herbst-Kralovetz et al., 2008).

Abbreviations: ECs, epithelial cells; FRT, female reproductive tract; FSL-1, fibroblast stimulating lipopeptide-1; IL-36, interleukin-36; IL-36R, IL-36 receptor, KSFM, keratinocyte serum-free medium; PBST, PBS-0.05\%Tween-20; qRT-PCR, quantitative real-time polymerase chain reaction; rIL-36 $\gamma$, recombinant IL-36 $\gamma$, STI, sexually transmitted infection. 
To better understand immune function of the human FRT at these two sites, we investigated a newly characterized IL-1 family member identified to play a role in chronic inflammation and disease at other mucosal sites (Dunn et al., 2001; Gabay and Towne, 2015). The IL-36 family is a group of cytokines whose members are known for their role in mediating inflammation and host defense (Dunn et al., 2001; Gresnigt and van de Veerdonk, 2013; Gresnigt et al., 2013). While IL-36 family members have been shown to be expressed and secreted by the epithelium lining the lungs, gut and skin, this family, to our knowledge, has not previously been investigated in the human FRT (Chustz et al., 2011; Johnston et al., 2011; Gabay and Towne, 2015; MedinaContreras et al., 2016). There are three isoforms that comprise the IL-36 family; IL-36 $\alpha$ (IL-1F7), IL-36 $\beta$ (IL-1F8), and IL-36 $\gamma$ (IL-1F9) and these cytokines are expressed in a more tissuerestricted fashion relative to IL-1 (Dunn et al., 2001; Gresnigt and van de Veerdonk, 2013). Of the three isoforms, IL-36 $\gamma$ has the highest expression levels in damaged or infected epithelium that lines the skin and lungs suggesting that it plays a role in epithelial immune response (Berglof et al., 2003; Lian et al., 2012; Gabay and Towne, 2015). As tissue becomes diseased, IL-36 $\gamma$ promotes inflammation by binding to the IL-36 receptor (IL36R) and stimulating the production of a number of cytokines, chemokines, adhesion molecules, antimicrobial peptides, and pro-inflammatory mediators (Towne et al., 2004; Vigne et al., 2011; Gresnigt and van de Veerdonk, 2013). Triggering IL-

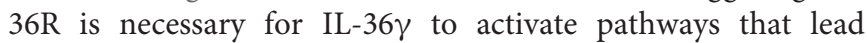
to induction of pro-inflammatory cytokine expression via NF$\kappa \mathrm{B}$ and MAPKs pathways (Chustz et al., 2011; Towne et al., 2011).

Vaginal and endocervical EC express pattern recognition receptors (PRRs) that can be triggered by sensing microbial products associated with bacteria and viruses resulting in an innate immune response (Herbst-Kralovetz et al., 2008). EC of the lower FRT respond to microbial products by secreting cytokines, chemokines, and antimicrobial peptides (Hjelm et al., 2010; Radtke et al., 2012; Doerflinger et al., 2014). Toll-like receptors (TLRs) expressed in FRT EC recognize microbeassociated molecular patterns (MAMPs) that correspond to highly conserved microbial products. Recent studies have shown that TLR agonists including polyinosinic-polycytidylic acid [poly (I:C); viral product] and flagellin (bacterial product) upregulate IL-36 $\gamma$ production in human skin keratinocytes, but have differential effects on IL-36 $\gamma$ secretion (Lian et al., 2012). Similar to IL- $1 \beta$ and IL-18, the IL-36 family members require processing to gain full bioactivity, the enzyme required is yet to be identified (Towne et al., 2011; Gabay and Towne, 2015). While both

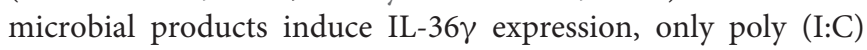
has been shown to induce secretion (Lian et al., 2012). As FRT EC express TLRs 2, 3, 5, and 6 at the highest levels (HerbstKralovetz and Pyles, 2006), we tested poly (I:C; TLR3 agonist), flagellin (TLR5 agonist), and FSL-1 (bacterial product; TLR2/6

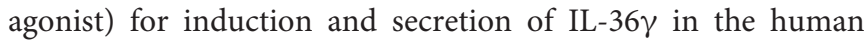
FRT.

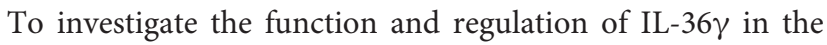
FRT, we used our well-characterized 3-D human vaginal and endocervical EC models (Barrila et al., 2010; Hjelm et al., 2010;
Radtke et al., 2012; Doerflinger et al., 2014). These models faithfully recapitulate many of the physiologic traits of FRT EC, including cellular architecture, adhesion, interaction, and immune function (Hjelm et al., 2010; Radtke et al., 2012; McGowin et al., 2013; Doerflinger et al., 2014). Furthermore, these two models can be used to evaluate site-specific differences in the magnitude and/or pattern of immune response at these sites. FRT EC models were exposed to microbial products to measure innate inflammatory responses in the FRT via induction and secretion of IL-36 $\gamma$. In addition, we investigated the autocrine function of IL-36 $\gamma$ in these 3-D FRT human EC by treating with rIL-36 $\gamma$. This is the first report to demonstrate that IL-36 receptor and IL-36 $\gamma$ are both expressed by ECs lining the human lower FRT and important in regulating host defense and immune responses in a TLR and site-specific manner.

\section{MATERIALS AND METHODS}

\section{Culturing 3-D Human Vaginal and Endocervical Epithelial Cells}

Human endocervical (A2) ECs were added to a suspension of collagen-coated dextran microcarrier beads (Sigma-Aldrich, St. Louis, MO, USA) in KSFM (Life Technologies, Grand Island, NY, USA) supplemented with $5 \mathrm{ng} / \mathrm{ml}$ human recombinant epidermal growth factor, $500 \mu \mathrm{g} / \mathrm{ml}$ bovine pituitary extract, $44 \mu \mathrm{g} / \mathrm{ml}$ $\mathrm{CaCl}_{2}$ (Sigma-Aldrich), and $100 \mu \mathrm{g} / \mathrm{ml}$ primocin (InvivoGen, San Diego, CA, USA) as previously described (Radtke et al., 2012). Human vaginal (V19I) EC were added to a suspension of collagen-coated dextran microcarrier beads in a 1:1 mixture of supplemented KSFM and EpiLife medium (Life Technologies) as previously described (Hjelm et al., 2010). Cell and bead suspensions were transferred into a slow turning lateral vessel bioreactor and incubated at $37^{\circ} \mathrm{C}$ as previously described (Hjelm et al., 2010; Radtke and Herbst-Kralovetz, 2012; Radtke et al., 2012). After 28 days of growth, differentiated endocervical and vaginal aggregates were quantified using a Countess machine (Life Technologies) and viability was measured by trypan blue exclusion.

\section{Human Cervical and Vaginal Epithelial Tissue Total RNA and Protein}

Human cervical and vaginal total protein samples and human cervical and vaginal total RNA samples were purchased from BioChain (Newark, CA, USA). According to BioChain, human vaginal total protein and total RNA samples were acquired from a post-menopausal Caucasian female. Human cervical total protein samples were acquired from a pre-menopausal Asian female and human cervical total RNA samples were acquired from a pre-menopausal Caucasian female (BioChain). As per Biochain, all analyzed tissues were determined to be nondiseased per the clinical report and were screened by serology for HIV, HBV, HCV, and HTLV. cDNA was synthesized from total RNA $(1 \mu \mathrm{g})$ cDNA by reverse transcription (iScript cDNA Synthesis Kit, Bio-Rad, Hercules, CA, USA) prior to qRT-PCR assays. 


\section{TLR Agonist and Cytokine Treatment}

For all experimental treatments, 3-D aggregates were transferred into 24 -well plates $\left(1 \times 10^{5}-5 \times 10^{5}\right.$ cells per $\left.\mathrm{ml}\right)$. Both $3-\mathrm{D}$ vaginal $\mathrm{EC}$ and $3-\mathrm{D}$ endocervical $\mathrm{EC}$ were treated with poly (I:C; InvivoGen) at 1, 25, and $100 \mu \mathrm{g} / \mathrm{ml}$, flagellin (InvivoGen) at 0.5 and $5 \mu \mathrm{g} / \mathrm{ml}, \mathrm{FSL}-1$ (InvivoGen) at 0.01 and $0.1 \mu \mathrm{g} / \mathrm{ml}$,

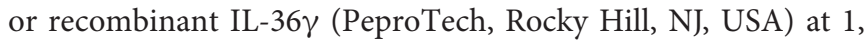
10,100 , and $500 \mathrm{ng} / \mathrm{ml}$ for $24 \mathrm{~h}$ at $37^{\circ} \mathrm{C}$. Additional wells were treated with sterile Dulbecco's PBS to provide a negative control. Following cell culture treatment, supernatants were harvested and stored at $-20^{\circ} \mathrm{C}$ until analysis. Cell pellets were stored at $-20^{\circ} \mathrm{C}$ in lysis buffer for RNA or protein extraction.

\section{Protein Extraction and Quantification}

For protein extraction, aggregates were pelleted and stored at $-20^{\circ} \mathrm{C}$ in $1 \mathrm{ml}$ of RIPA buffer $[150 \mathrm{mM} \mathrm{NaCl}$ (Thermo Fisher Scientific), 50 mM Tris-HCL pH 8.0 (Life Technologies), 1 mM EDTA (Life Technologies), 1\% NP-40 (Sigma-Aldrich), $1 \%$ sodium deoxycholate (Sigma-Aldrich), 0.1\% SDS (SigmaAldrich), $1 \mathrm{mM}$ PMSF (Sigma-Aldrich), and $5 \mu \mathrm{g} / \mathrm{ml}$ leupeptin (Sigma-Aldrich)]. Frozen cell pellets were thawed on ice. Once thawed, cells were incubated for 10 min on ice with intermittent mixing by inversion. Next, cells were sheared with a 23-gage needle connected to a $1 \mathrm{ml}$ syringe. After incubating on ice for $20 \mathrm{~min}$, cells were pelleted at $10,000 \times g$ and supernatant was removed. A Bradford assay was performed in a microtiter plate to determine total protein concentration of the extracted cell pellet and culture supernatant. Absorbance was read at $595 \mathrm{~nm}$ on a Biotek ELx800 Microplate Reader (BioTek, Winooski, VT, USA) and experimental values were compared to the calculated standard curve to acquire total protein concentration.

\section{ELISA Quantification of Intracellular and Secreted Human IL-36y}

High binding microtiter plates (Corning, Tewksbury, MA, USA) were coated with $50 \mu \mathrm{l} /$ well of monoclonal rat anti-human IL$36 \gamma$ antibody (R\&D Systems, Minneapolis, MN, USA) at $2 \mu \mathrm{g} / \mathrm{ml}$ in PBS and incubated overnight at $4^{\circ} \mathrm{C}$. The microtiter plates were washed three times with PBS-0.05\%Tween-20 (PBST) then $50 \mu \mathrm{l}$ of twofold serial dilutions of recombinant human IL$36 \gamma$ (rIL-36 $\gamma$, PeproTech) was added in duplicate to generate a standard curve. Experimental samples were added to each well in duplicate and all samples were incubated for $2 \mathrm{~h}$ at $37^{\circ} \mathrm{C}$. The microtiter plates were then washed three times with PBST then biotinylated polyclonal goat anti-human IL-36 $\gamma$ detection antibody (R\&D Systems) diluted at $2 \mu \mathrm{g} / \mathrm{ml}$ with $1 \%$ skim milk in PBST was added to each well and incubated for $2 \mathrm{~h}$ at $37^{\circ} \mathrm{C}$. Following the incubation, the plates were washed with PBST three times. After washing, $50 \mu 1$ streptavidin-HRP (R\&D Systems) was added at a 1:250 dilution in PBST to each well and incubated for $1 \mathrm{~h}$ at $37^{\circ} \mathrm{C}$. The plates were washed three times with PBST and then developed by addition of $50 \mu \mathrm{l}$ tetramethylbenzidine substrate solution (Thermo Fisher Scientific, Waltham, MA, USA) to each well and incubated in the dark for up to $30 \mathrm{~min}$ at room temperature. The colorimetric reaction was stopped by addition of $50 \mu \mathrm{l} /$ well of $1 \mathrm{M}$ phosphoric acid and absorbance read at $450 \mathrm{~nm}$ on a Biotek ELx800 Microplate Reader (BioTek). Results were reported in fold as compared to PBS treated cell extracts.

\section{Human IL-36y Western Blot Analysis}

Cell culture supernatants and cell pellet extracts were boiled for $10 \mathrm{~min}$ in $2 \times$ SDS buffer (6\% SDS, $25 \mathrm{mM}$ Tris-HCL pH 6.5, 10\% glycerol, $0.1 \mathrm{M} \mathrm{DTT}, 20 \mu \mathrm{g} / \mathrm{ml}$ bromophenol blue). Total protein (30 $\mu \mathrm{g})$ was loaded into $4-15 \%$ polyacrylamide Mini-PROTEAN TGX precast gels (Bio-Rad). After proteins were separated by SDS-PAGE, gels were transferred to polyvinylidene diflouride membranes (Life Technologies) using a dry blotting system (iBlot, Life Technologies). Levels of IL-36 $\gamma$ were determined using biotinylated goat anti-human IL-36 $\gamma$ diluted to $4 \mu \mathrm{g} / \mathrm{ml}$ in PBST with $1 \%$ dry milk, followed by streptavidin-HRP diluted 1:250 (R\&D Systems). Levels of $\beta$-tubulin were examined using mouse anti- $\beta$-tubulin (Santa Cruz, Biotechnology, Dallas, TX, USA) diluted 1:1000 with horseradish peroxidase labeled goat anti-mouse (Santa Cruz Biotechnology) as a secondary antibody. Membranes were developed using ECL substrate (Life Technologies).

\section{Quantification of Human Cytokines and Chemokines by Multiplex Analysis}

Supernatants from 3-D vaginal and endocervical EC aggregates treated with rIL-36 $\gamma$ as described above were collected cytokine secretion levels were quantified. Cytokine concentrations were determined using a custom four-plex human cytokine kit containing IL-1B, IL-6, CCL20, and TNF $\alpha$ (EMD Millipore, Billerica, MA, USA) using the manufacturer's protocol. The data were collected using a Bio-Plex 200 System with Bio-Plex 5.0 Manager software (Bio-Rad).

\section{RNA Extraction and Quantitative Real-Time PCR Analysis}

RNA was extracted from 3-D endocervical and 3-D vaginal EC using the Qiagen RNeasy kit following the manufacturer's instructions (Qiagen, Valencia, CA, USA). cDNA was synthesized from $1 \mu \mathrm{g}$ RNA by reverse transcription (iScript cDNA Synthesis Kit, Bio-Rad) and analyzed by qRT-PCR. qRT-PCR was performed with an Applied Biosystems 7500 Fast Real Time PCR System (Life Technologies) using customized primers purchased from IDT (Integrated DNA Technologies, Coralville, IA, USA) and iTAQ Universal SYBR Green Supermix (Bio$\mathrm{Rad})$. The following primers were used in this study: IL- $1 \beta$ forward, 5'-ACAGATGAAGTGCTCCTTCCA-3' and reverse $5^{\prime}$-GTCGGAGATTCGTAGCTGGAT-3' (Stordeur et al., 2002), HE4 forward 5'-CGGCTTCACCCTAGTCTCAG-3' and reverse $5^{\prime}$-AAAGGGAGAAGCTGTGGTCA-3' (Drapkin et al., 2005), IL-36 $\gamma$ forward 5'-CCCAGTCACTGTTGCTGTTA-3' and reverse $5^{\prime}$-CAGTCTTGGCACGGTAGAAA-3', IL-36R forward 5'-GCTGGAGTGTCCACAGCATA-3' and reverse 5'-GCGATAAGCCCTCCTATCAA-3' (Mutamba et al., 2012). IL-6, IL-8, HBD2, HBD4, and SLPI primers were previously described (Radtke et al., 2012; Doerflinger et al., 2014). Relative transcript levels were determined using a GAPDH housekeeping 
gene transcript and are reported as fold relative to negative control unless otherwise noted.

\section{Statistical Analysis}

All of the data for this study was generated using three independent batches of 3-D endocervical or vaginal EC aggregates in three independent experiments, and an average of all three of these experimental results are presented. An unpaired two-tailed Student $t$-test with Welch's correction was performed to determine statistical significance. GraphPad Prism v5.0 software was used for statistical analysis (GraphPad, San Diego, CA, USA). Levels of significance are reported as follows; ${ }^{\wedge} P<0.05 ;{ }^{*} P<0.01 ;{ }^{* *} P<0.001$.

\section{RESULTS}

\section{Human Tissue and 3-D Vaginal and Endocervical EC Express IL-36 $\gamma$ and IL-36R}

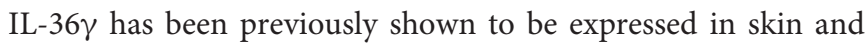
ECs lining mucosal tissue (Jensen, 2010; Chustz et al., 2011; Gabay and Towne, 2015), however, this cytokine has not been

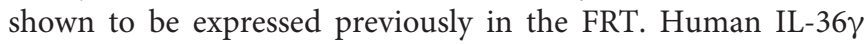
levels were measured in both 3 -D vaginal and endocervical EC by qRT-PCR analysis. Untreated 3-D vaginal and endocervical $\mathrm{EC}$, and human cervical and vaginal tissue were analyzed by qRT-PCR assays targeting IL-36 $\gamma$ and IL-36R (Figure 1A). Basal expression of IL-36 $\gamma$ was significantly $(P<0.001)$ higher in 3-D endocervical EC compared to 3-D vaginal EC. Human 3-D vaginal and endocervical EC, as well as, human vaginal and cervical tissue expressed IL-36 $\gamma$ at levels much higher than
IL-36R (Figure 1A). This is the first report to characterize IL-36R and IL-36 $\gamma$ in the EC lining the human FRT, furthermore, these results demonstrate our model's ability to serve as a tool to further study IL-36 function.

Western blots were performed to confirm production/

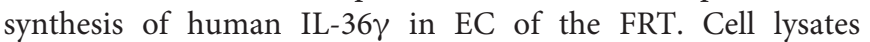
from human 3-D vaginal and endocervical EC models and cell lysates from human cervical and vaginal tissue, were analyzed by Western blot (Figure 1B). We found that IL-36 $\gamma$ was constitutively produced in human $3-\mathrm{D}$ vaginal and endocervical EC and vaginal and endocervical tissue. Basal synthesis of IL-36R was lower than the detection limits of Western blot analysis (data not shown) in both PBS treated and TLR agonist stimulated FRT

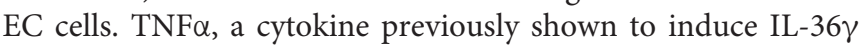
(Friedrich et al., 2014), was used as a positive control to test if IL$36 \gamma$ is inducible in the FRT EC. Three-D vaginal and endocervical EC were treated with TNF $\alpha$ for $24 \mathrm{~h}$. Following TNF $\alpha$ treatment, IL-36 $\gamma$ gene expression levels in $3-\mathrm{D}$ vaginal and endocervical EC were significantly $(P<0.001)$ increased 32 -fold, and 19.6fold respectively (Figure 1C). The $3-\mathrm{D}$ vaginal EC and tissue exhibited higher baseline levels of IL-36 $\gamma$ and IL-36R relative to 3-D endocervical EC and tissue and $\mathrm{TNF} \alpha$ treatment induced higher levels of IL-36 $\gamma$ expression in $3-\mathrm{D}$ vaginal EC relative to the endocervical EC.

\section{Microbial Products Differentially Induce IL-36y Expression and Secretion in EC of the Human FRT}

Microbial products elicit potent immune responses in EC of the FRT through ligation with TLRs. We have previously shown that TLR agonists: poly(I:C; viral product and TLR3 agonist), flagellin (bacterial product and TLR5 agonist), and

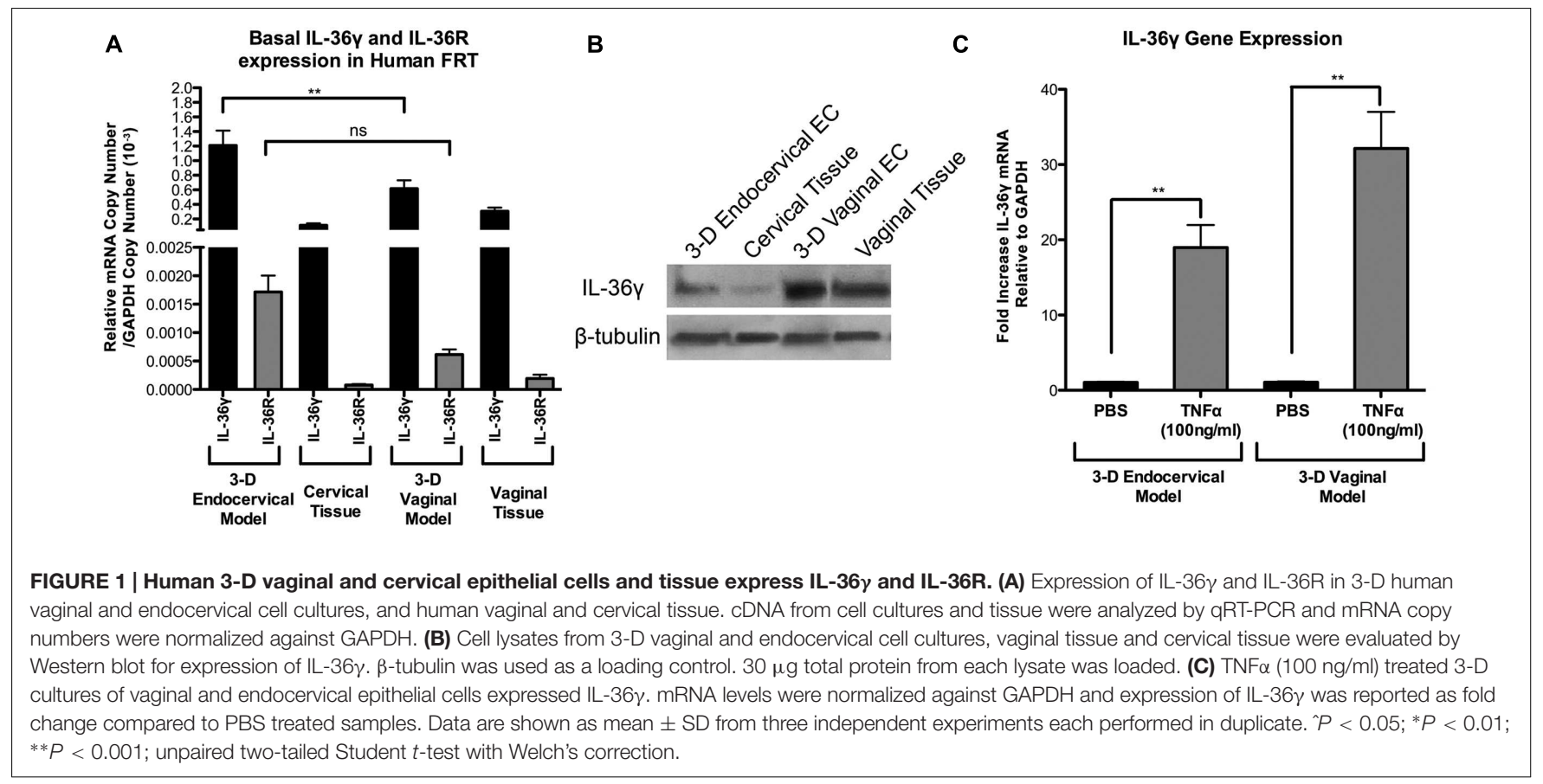


FSL-1 (bacterial product and TLR2/6 agonist) induce cytokine expression and secretion in primary and immortalized vaginal and endocervical EC grown as monolayers and in 3-D (HerbstKralovetz et al., 2008; Hjelm et al., 2010; Radtke et al., 2012; Doerflinger et al., 2014). These studies have also shown that TLRs $2,3,5$, and 6 are abundantly expressed in these cell lines and these TLRs remain functional and responsive when cultured under rotating conditions (Herbst-Kralovetz et al., 2008; Hjelm et al., 2010; Radtke and Herbst-Kralovetz, 2012; Radtke et al., 2012). Maximal cytokine induction was detected $24 \mathrm{~h}$ after treatment of microbial products in these studies, hence we focused on that time point herein (Herbst-Kralovetz et al., 2008). Human 3-D vaginal and endocervical EC were treated with a panel of microbial products for $24 \mathrm{~h}$, and IL-36 $\gamma$ expression levels were quantified by qRT-PCR analysis (Figure 2). Following poly (I:C), FSL-1, and flagellin treatment did not result in cellular adherence to beads as observed by light microscopy and cellular viability was not decreased by more than $10 \%$ as measured by trypan blue exclusion (data not shown). IL-36 $\gamma$ expression increased following treatment with each microbial product in a concentration dependent manner. We observed that poly (I:C)

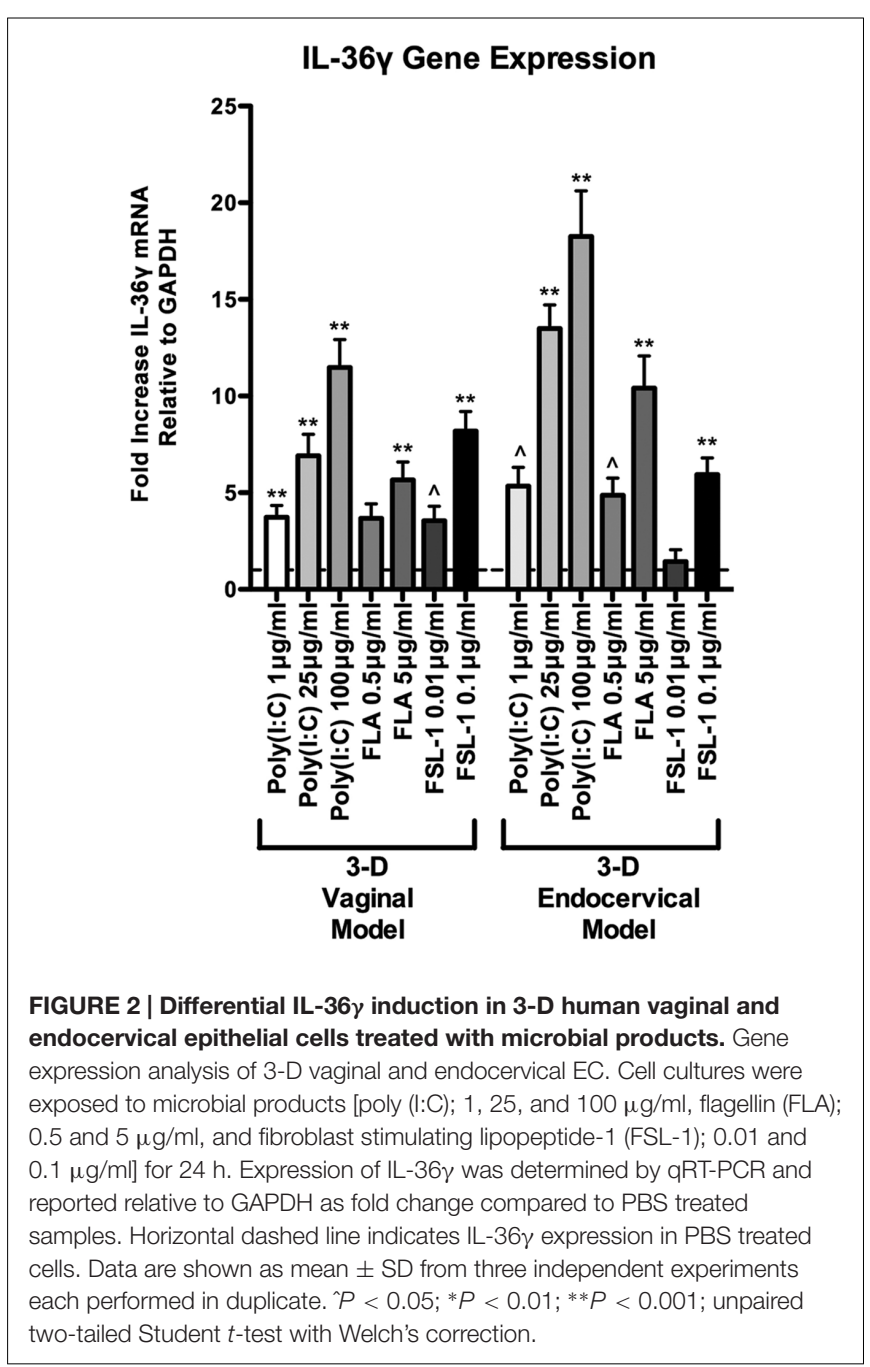

induced the highest amount of IL-36 $\gamma$ gene expression in both cell types (Figure 2). In 3-D vaginal EC IL-36 $\gamma$ expression was induced by treatment with poly (I:C; $100 \mu \mathrm{g} / \mathrm{ml}$ ), flagellin (5 $\mu \mathrm{g} / \mathrm{ml})$, and FSL-1 $(0.1 \mu \mathrm{g} / \mathrm{ml})$ by $10.2-, 5.1-$, and 8.9 -fold, respectively. Endocervical EC treated with poly (I:C), flagellin, and FSL- 1 also resulted in significant increases $(P<0.001)$ in IL$36 \gamma$ expression levels at 20.2-, 11.7-, and 7-fold, respectively. Poly (I:C) and flagellin induced higher levels of IL-36 $\gamma$ expression in 3 -D endocervical EC relative to vaginal EC $(P<0.001)$.

Since IL-36 $\gamma$ mRNA levels increased in a dose dependent manner, we performed an IL-36 $\gamma$ targeted ELISA to quantify protein levels following treatment with these microbial products. After treatment with the poly (I:C), flagellin, FSL-1, and PBS, cell lysates and cellular supernatants were collected and assayed for IL-36 $\gamma$ by ELISA. Poly (I:C), flagellin, and FSL-1 treatments induced IL-36 $\gamma$ production in a dose dependent manner in both 3-D vaginal and 3-D endocervical EC when compared to PBS treated controls (Figure 3B). All of the microbial products tested induced an increase in IL-36 $\gamma$ mRNA in 3-D FRT EC, however, the magnitude of protein production and secretion levels were microbial product specific. Treatment with higher concentrations of poly (I:C) resulted in higher levels of secreted IL-36 $\gamma$ in 3$D$ vaginal and endocervical EC (Figures 3A,B) when measured by ELISA. Flagellin induced a significant increase $(P<0.01)$ in intracellular IL-36 $\gamma$ production in vaginal and endocervical $(P<0.01)$ EC. Poly (I:C) induced significant levels of IL-36 $\gamma$ secretion by vaginal $(1 \mu \mathrm{g} / \mathrm{ml} ; P<0.01,25 \mu \mathrm{g} / \mathrm{ml} ; P<0.001$, and $100 \mu \mathrm{g} / \mathrm{ml} ; P<0.001)$ and endocervical $(1 \mu \mathrm{g} / \mathrm{ml}$; [not significant (NS)] $25 \mu \mathrm{g} / \mathrm{ml} ; P<0.001$, and $100 \mu \mathrm{g} / \mathrm{ml} ; P<0.001)$ EC. FSL-1 induction of intracellular IL-36 $\gamma$ production significantly

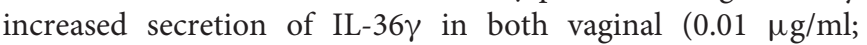
$P<0.01,0.01 \mu \mathrm{g} / \mathrm{ml} ; P<0.001)$ and endocervical $(0.01 \mu \mathrm{g} / \mathrm{ml}$; $P<0.01,0.01 \mu \mathrm{g} / \mathrm{ml} ; P<0.001)$ EC. Less IL-36 $\gamma$ secretion occurred following treatment with flagellin relative to control treated cells.

IL-36 $\gamma$ probed Western blots were performed to verify ELISA results. FRT EC were treated with poly (I:C), flagellin, and FSL-1 in increasing concentrations for $24 \mathrm{~h}$. Both the supernatant and extracted cell pellets of TLR agonist treated FRT EC were analyzed to measure intracellular and secreted

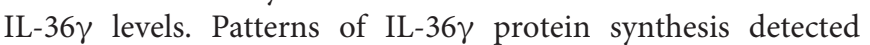
by Western blot mirrored the quantitative data generated by ELISA, supporting the protein production profiles of FRT EC (Supplementary Figure S1). Poly (I:C) and FSL-1 treatment resulted in the highest induction of secreted IL-36 $\gamma$ levels relative to untreated wells by ELISA and Western blot, whereas flagellin treatment induced significantly higher intracellular levels of IL$36 \gamma$ (Figure 3 and Supplementary Figure S1). As such, there was an inverse relationship between IL-36 $\gamma$ induction by these microbial products.

\section{Recombinant IL-36y Induces an Autocrine IL-36y Loop in Human 3-D Vaginal and Endocervical EC}

IL-36 $\gamma$ has been shown to induce expression of itself, thereby exhibiting an autocrine signaling loop in keratinocytes (Lian 


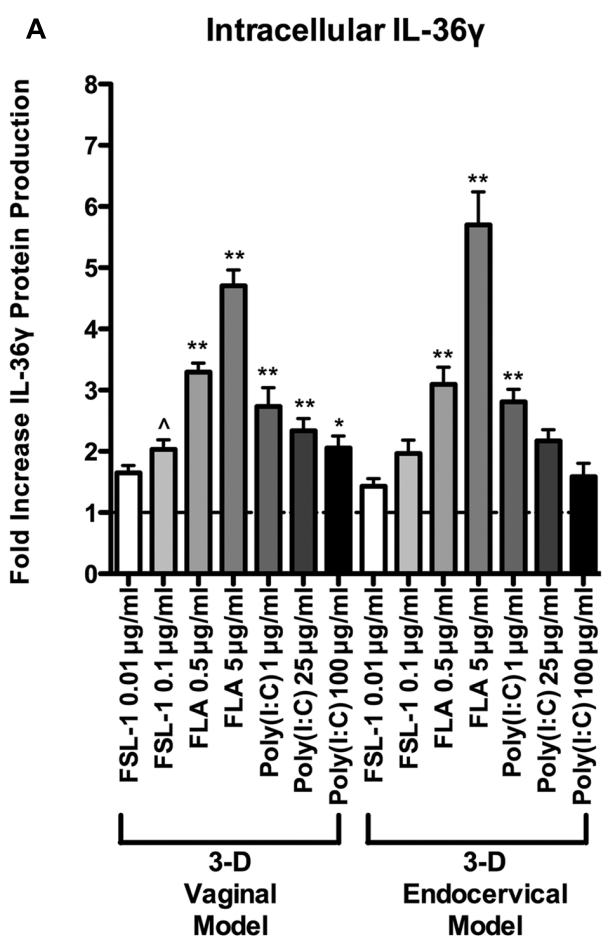

B

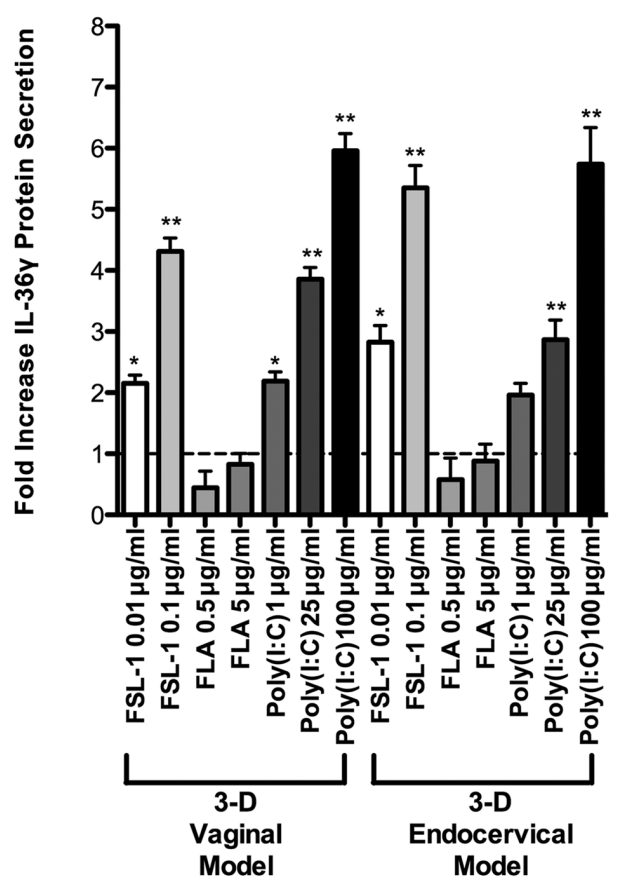

FIGURE 3 | Extracellular and intracellular localization of IL-36 $\gamma$ in epithelial cells of the human female reproductive tract following treatment with

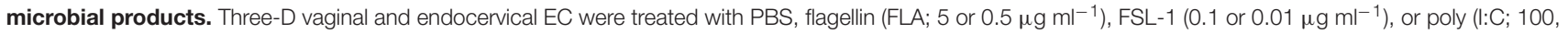
25, or $1 \mu \mathrm{g} \mathrm{ml}^{-1}$ ) for $24 \mathrm{~h}$. (A) Cell culture lysates and (B) supernatants were assayed by ELISA to quantify IL-36 $\gamma$ production and secretion. Levels of IL-36 $\gamma$ were determined and reported as fold change relative to PBS treated samples. Horizontal dashed line indicates IL-36 $\gamma$ expression in PBS treated cells. Data are shown as mean \pm SD from three independent experiments each performed in duplicate. ${ }^{P} P<0.05$; ${ }^{*} P<0.01$; ${ }^{* *} P<0.001$; unpaired 2 -tailed Student $t$-test with Welch's correction.

et al., 2012). Three-D vaginal and endocervical EC were treated

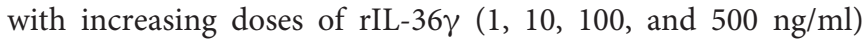
for $24 \mathrm{~h}$. qRT-PCR assays targeting IL-36 $\gamma$ and IL-36R was performed following treatment with rIL-36 $\gamma$. We observed a significant increase in IL-36 $\gamma$ gene expression in both 3 - $D$ vaginal $(10 \mathrm{ng} / \mathrm{ml} ; P<0.001,100 \mathrm{ng} / \mathrm{ml} ; P<0.001,500 \mathrm{ng} / \mathrm{ml} ; P<0.001)$ and endocervical EC $(10 \mathrm{ng} / \mathrm{ml} ; P<0.01,100 \mathrm{ng} / \mathrm{ml} ; P<0.001$, $500 \mathrm{ng} / \mathrm{ml} P<0.001$; Figure 4A). A similar pattern in IL$36 \mathrm{R}$ expression in $3-\mathrm{D}$ vaginal $[10 \mathrm{ng} / \mathrm{ml} ; 4.2$-fold $(P<0.01)$, $100 \mathrm{ng} / \mathrm{ml} ; 7.9$-fold $(P<0.001), 500 \mathrm{ng} / \mathrm{ml} ; 10.4$-fold $(P<0.001)]$ and endocervical EC $[10 \mathrm{ng} / \mathrm{ml} ; 8.3$-fold $(P<0.05), 100 \mathrm{ng} / \mathrm{ml}$; 13.9-fold ( $P<0.01), 500 \mathrm{ng} / \mathrm{ml}$; 15.7-fold $(P<0.001$; Figure 4B)] was observed, albeit at lower levels. The fold increases in both IL-36 $\gamma$ and IL-36R were dependent on rIL-36 $\gamma$ treatment concentration and expression levels were higher in the 3-D endocervical EC compared to the vaginal EC.

\section{Pro-inflammatory Cytokine and Antimicrobial Peptide Production in 3-D FRT EC is Increased Following Recombinant IL-36 $\gamma$ Treatment}

We have shown that microbial products induce IL-36 $\gamma$ and influence its secretion. To examine the role IL-36 $\gamma$ plays in triggering inflammatory signaling pathways in FRT EC and to determine if it is concentration dependent, we treated 3-D endocervical and vaginal EC with rIL-36 $\gamma$. Treatment with rIL-36 $\gamma$ induced antimicrobial peptide, pro-inflammatory cytokine, and chemokine production in a dose dependent manner (Figures 5 and 6). IL-8 (Figure 5A) mRNA levels were significantly increased $(P<0.001)$ in both cell models following 100 and $500 \mathrm{ng} / \mathrm{ml} \mathrm{rIL-36 \gamma}$ treatments. rIL-36 $\gamma$ treatment $(500 \mathrm{ng} / \mathrm{ml})$ resulted in a significant difference $(P<0.001)$ in CCL20 production (Figure 5B) and 3-D vaginal EC CCL20 levels were significantly higher $(P<0.001)$ at $500 \mathrm{ng} / \mathrm{ml}$ compared to the 3-D endocervical EC. Antimicrobial peptides including HE4 (Figure 5C), SLPI (Figure 5D), HBD-2 (Figure 5E), and HBD-4 (Figure 5F) were significantly increased in a dose dependent manner following rIL-36 $\gamma$ treatments. Treatment with rIL-36 $\gamma$ at 100 and $500 \mathrm{ng} / \mathrm{ml}$ resulted in significant increases in HE4 in 3-D vaginal $(P<0.001$ and $P<0.01)$ and endocervical $(P<0.05$ and $P<0.001)$. SLPI mRNA levels increased at similar magnitudes following rIL-36 $\gamma$ treatments at 100 and $500 \mathrm{ng} / \mathrm{ml}$ in $3-\mathrm{D}$ vaginal $(P<0.001)$ and endocervical $(P<0.05)$ EC.

Of these AMP, two notable site-specific differences were observed in the induction HBD-2 and HBD-4 in 3-D FRT EC following treatment with100 and $500 \mathrm{ng} / \mathrm{ml}$ of rIL-36 $\gamma$. Fold values for 3-D vaginal cells were higher for HBD-2 and HBD-4 relative to endocervical EC. HBD-2 increased 12.7-fold 

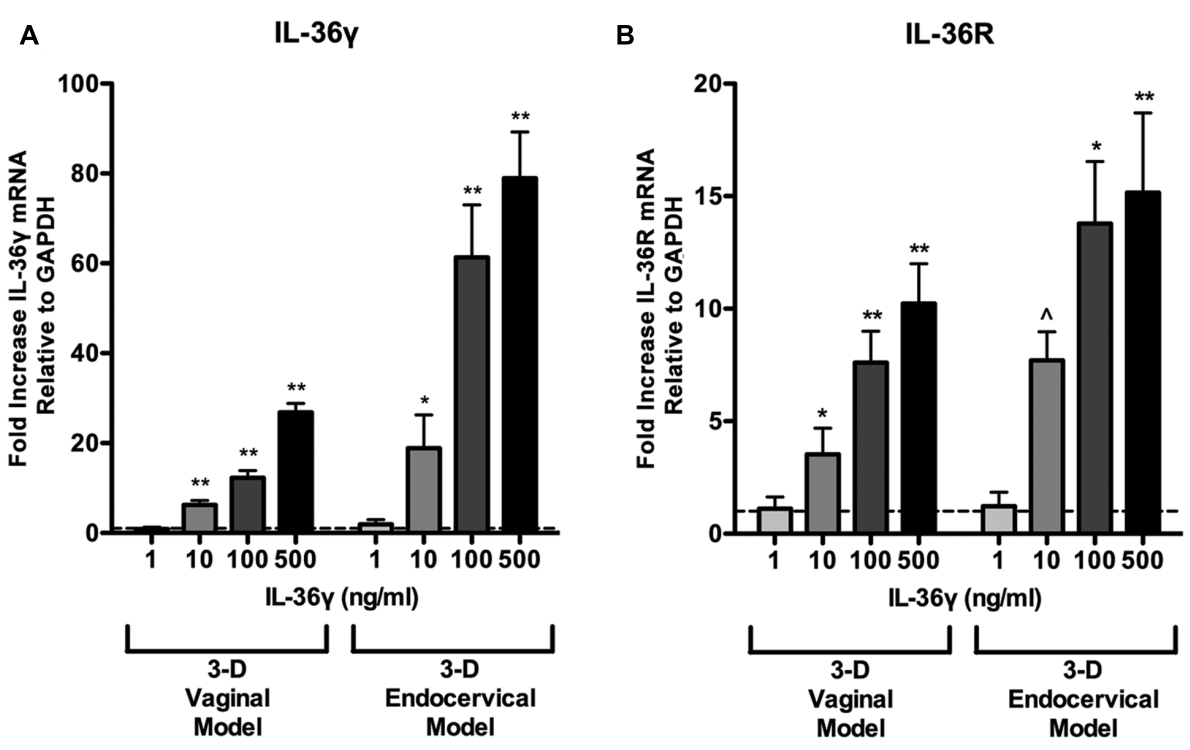

FIGURE 4 | Induction of IL-36 $\gamma$ and IL-36R expression following recombinant IL-36 $\gamma$ treatment. 3-D vaginal and endocervical EC were treated with

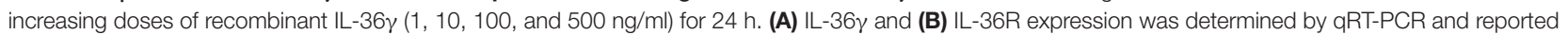
relative to GAPDH as fold change compared to PBS treated samples. Horizontal dashed line indicates IL-36 $\gamma$ expression in PBS treated cells. Data are shown as mean \pm SD from three independent experiments each performed in duplicate. ${ }^{\wedge} P<0.05 ;{ }^{*} P<0.01 ;{ }^{* *} P<0.001$; unpaired two-tailed Student $t$-test with Welch's correction.

$(P<0.001)$ and 39.4-fold $(P<0.001)$ and HBD-4 mRNA was increased 24.6-fold $(P<0.001)$ and 55.4-fold $(P<0.001)$ in 3$\mathrm{D}$ vaginal EC, respectively. rIL-36 $\gamma$ treated 3-D endocervical EC increased 6.9- and 18-fold at 100 and $500 \mathrm{ng} / \mathrm{ml}$, respectively, for HBD-2 at 15.6-fold $(P<0.001)$ and 31.8-fold $(P<0.001)$ for the HBD-4 gene. HBD 2 and HBD-4 expression was significantly higher in 3-D vaginal EC than 3-D endocervical EC following rIL$36 \gamma$ treatments at 100 and $500 \mathrm{ng} / \mathrm{ml}(P<0.05$ and $P<0.01$ respectively). SLPI and HE4, were the only AMP assayed that resulted in more robust response in endocervical EC when compared to vaginal EC, but these site specific differences in expression were not significant. IL-8 gene expression levels were similar in both cell types. CCL20 expression levels varied in the two cell types depending on the concentration of rIL-36 $\gamma$.

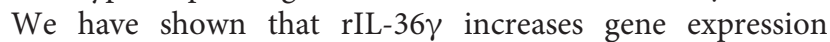
of chemokines and AMP. To quantify levels of additional proinflammatory cytokines and chemokines we assayed cell supernatants with a multiplex bead-based immunodetection assay. Secretion of IL-1 $\beta$, IL-6, CCL20, and TNF $\alpha$ was induced in a dose dependent fashion following $24 \mathrm{~h}$ treatments with rIL$36 \gamma$ (Figure 6). CCL20 secretion was significantly $(P<0.01)$ increased following treatment with rIL-36 $\gamma$ at 100 and $500 \mathrm{ng} / \mathrm{ml}$ in both $3-\mathrm{D}$ vaginal and endocervical EC. IL- $1 \beta$ secretion was significantly $(P<0.01)$ increased following rIL-36 $\gamma$ treatments at $500 \mathrm{ng} / \mathrm{ml}$ in $3-\mathrm{D}$ vaginal EC. rIL-36 $\gamma$ treatments at 100 and $500 \mathrm{ng} / \mathrm{ml}$ resulted in significant increases in IL-1 $\beta$ secretion $(P<0.05)$ in $3-\mathrm{D}$ endocervical EC as well. Secretion of IL6 was significantly $(P<0.01)$ increased in $3-\mathrm{D}$ vaginal EC following rIL-36 $\gamma$ treatments of 100 and $500 \mathrm{ng} / \mathrm{ml}$. IL-6 and $\mathrm{TNF} \alpha$ secretion was induced in 3-D endocervical EC, however, the magnitude of secretion was higher in $3-\mathrm{D}$ vaginal EC.
Secreted IL-6 increased from 86.48 to $552.9 \mathrm{pg} / \mathrm{ml}$ (NS) for $100 \mathrm{ng} / \mathrm{ml} \mathrm{rIL-36 \gamma}$ and $951.5 \mathrm{pg} / \mathrm{ml}(P<0.01)$ for $500 \mathrm{ng} / \mathrm{ml}$

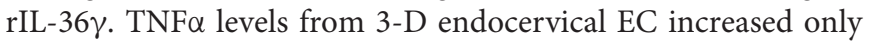
slightly following rIL-36 $\gamma$ treatments and the increase was not significant. Overall, pro-inflammatory cytokines, chemokines, and AMP were significantly induced in 3-D vaginal and cervical EC following treatment with rIL-36 $\gamma$. The pattern of cytokine and AMP induction was similar for vaginal and cervical cells and was also dose-dependent, but the magnitude was higher in the 3-D vaginal EC model relative to the $3-\mathrm{D}$ cervical model for most immune mediators evaluated.

\section{DISCUSSION}

This is the first report demonstrating a role for IL-36 $\gamma$ in host defense and amplification of the mucosal immune response by ECs lining the FRT. We showed that in the

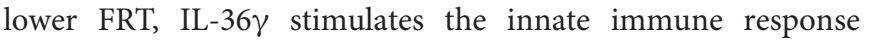
by induction of pro-inflammatory cytokines, chemokines, and AMP, thereby promoting mucosal inflammation. This study provides the foundation for future studies that aim to elucidate the mechanisms of IL-36 family members in the FRT during homeostasis, STI, disease pathogenesis, and reproductive sequelae.

Recent literature on IL-36 $\gamma$ has been primarily focused on chronic inflammatory processes that include psoriasis and chronic obstructive pulmonary disease (COPD), where IL-36 $\gamma$ was found to be abundantly expressed in the skin and the mucosal ECs of the lung (Li et al., 2014; Gabay and Towne, 2015) and result in sustained inflammation (Chustz et al., 2011; Gabay 


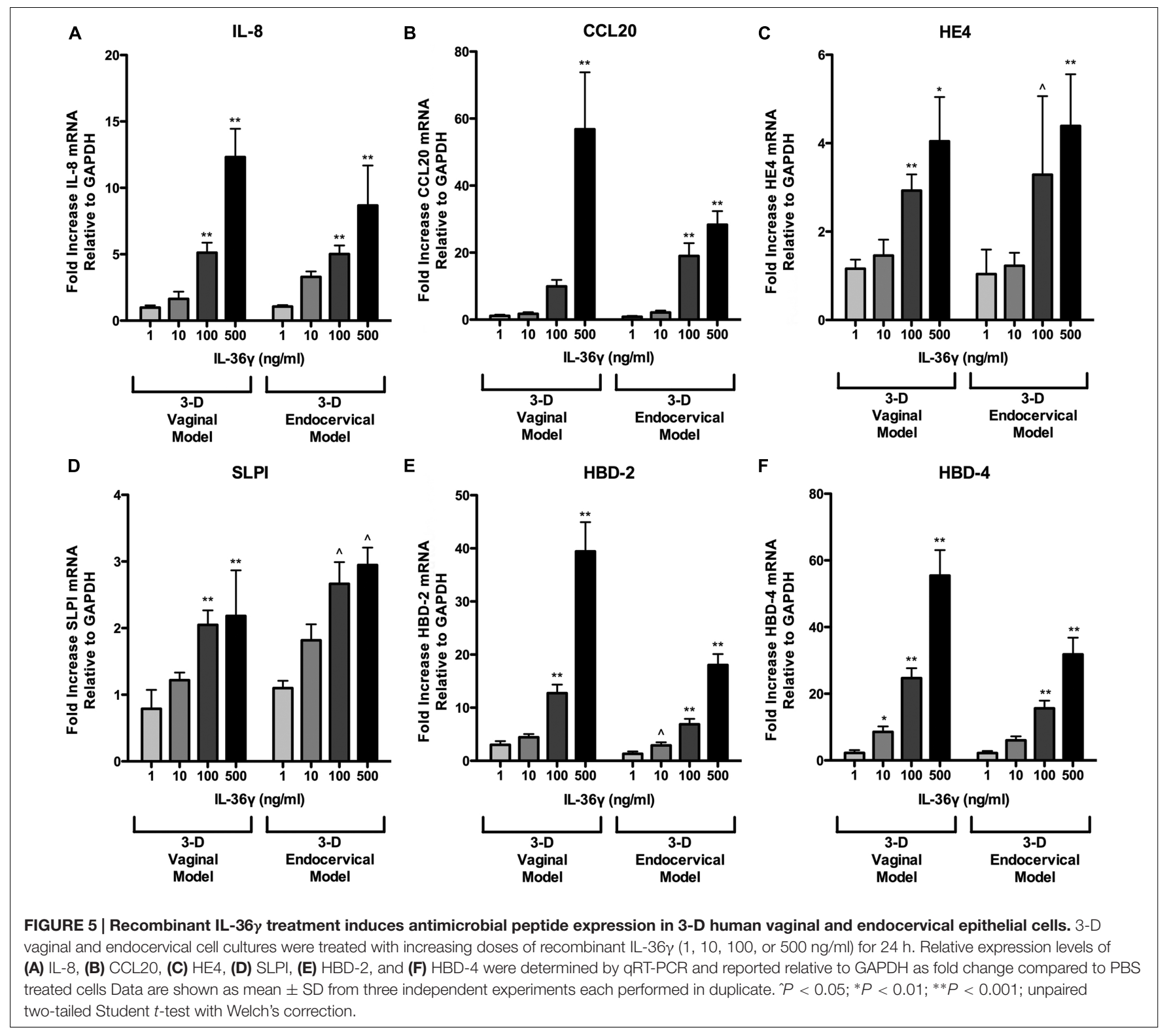

and Towne, 2015). However, there have been limited studies investigating the role of IL-36 $\gamma$ in host defense and infection at mucosal sites (Vos et al., 2005; Gresnigt et al., 2013; Segueni et al., 2015).

Herein we report that IL-36 $\gamma$ is expressed in human cervical and vaginal ECs and tissue. A limitation to the study evaluating IL-36 $\gamma$ and IL-36R in vaginal tissue, is the lack of availability of premenopausal non-diseased vaginal tissue. However, our data demonstrated that premenopausal cervical tissue and post-menopausal vaginal tissue both express IL-36 $\gamma$ and IL36R. Future studies will be required to determine the impact of sex hormones on this cytokine and associated receptor expression. Using our well-characterized human 3-D cervical and vaginal EC models we demonstrate that these cells respond

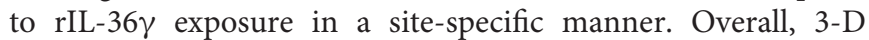
vaginal EC expressed and secreted higher levels of these innate immune mediators following rIL-36 $\gamma$ treatments relative to 3-D endocervical EC, however, this response did not seem to correspond to IL-36R expression (Figure 1).

IL-36 increases and prolongs inflammation through interaction with $\mathrm{TNF} \alpha$, a known inducer and inductee of IL-36 $\gamma$ (Towne and Sims, 2012). TNF $\alpha$ is expressed in excess in psoriatic lesions (Cuchacovich et al., 2008) leading to upregulation

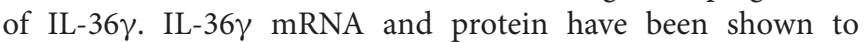
be induced in keratinocytes following treatment with $\mathrm{TNF} \alpha$ (Kumar et al., 2000). Consistent with findings in bronchial ECs

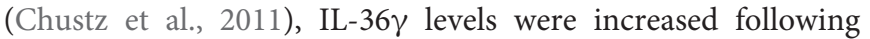
$\mathrm{TNF} \alpha$ treatment in 3-D FRT EC, demonstrating that expression

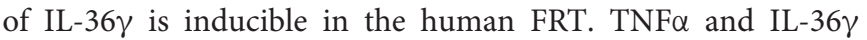
participate in a mutually reinforcing gene expression loop, initiated by IL-36 $\gamma, \mathrm{TNF} \alpha$, as well as other cytokines (Friedrich et al., 2014). Increased levels of TNF $\alpha$ have been shown to result 

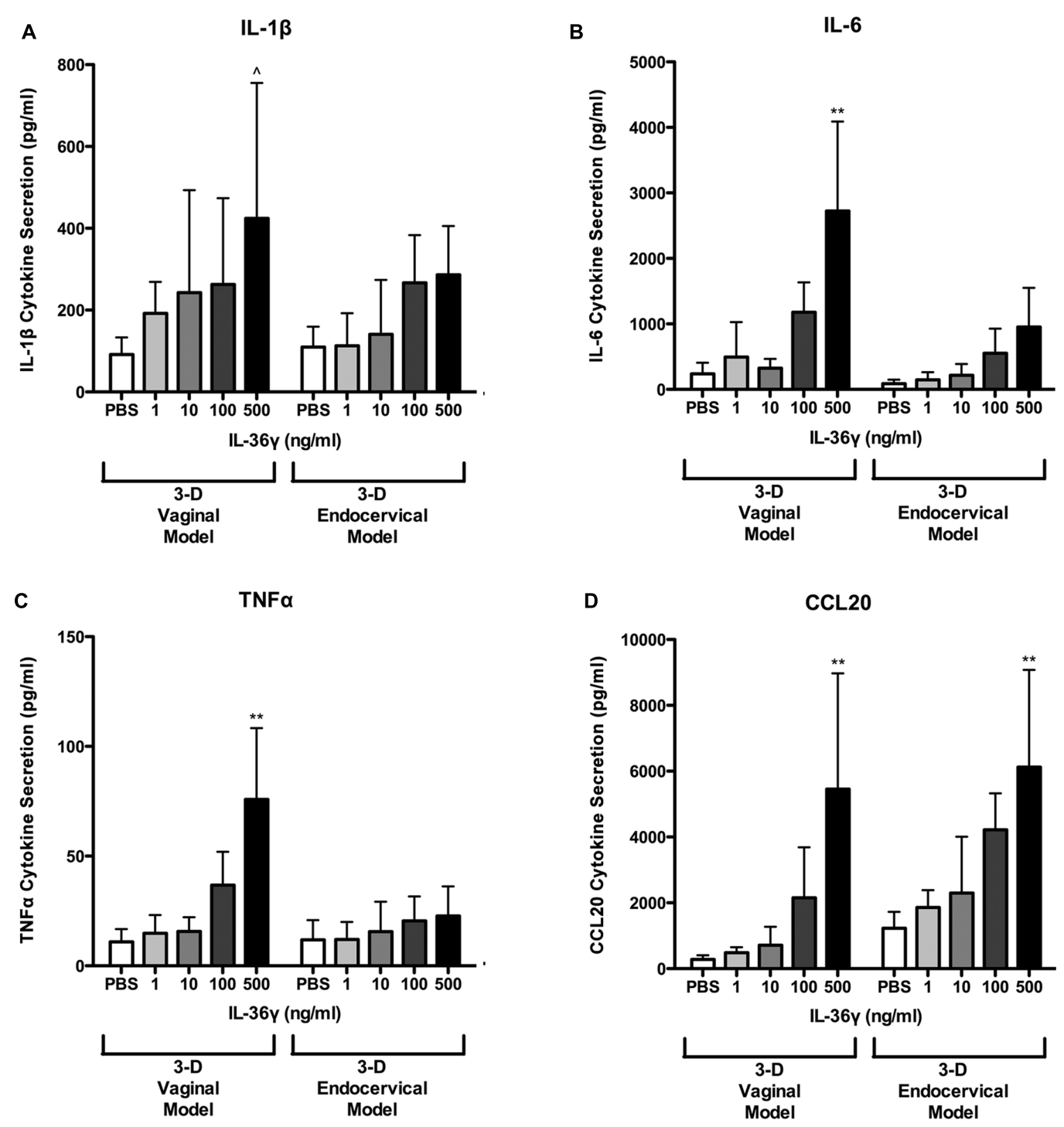

FIGURE 6 | 3-D human vaginal and endocervical epithelial cells secrete increased levels of pro-inflammatory cytokines and chemokines in response to treatment with recombinant IL-36y. 3-D vaginal and endocervical cell cultures were treated with PBS or increasing doses of recombinant IL-36 $\gamma$ (1, 10, 100, or $500 \mathrm{ng} / \mathrm{ml}$ ) for $24 \mathrm{~h}$. Expression levels of (A) IL-1 $\beta$, (B) IL-6, (C) TNF $\alpha$, and chemokine (D) CCL20 were determined by multiplex analysis and reported in pg/ml. Data are shown as mean \pm SD from three independent experiments each performed in duplicate. ${ }^{\wedge} P<0.05$; ${ }^{*} P<0.01$; ${ }^{* *} P<0.001$; unpaired two-tailed Student t-test with Welch's correction.

from microbial product exposure and pathogenic insults in the FRT (Jarvis et al., 1999; Agrawal et al., 2008; Hjelm et al., 2010; Radtke et al., 2012; Krzyzowska et al., 2013; Doerflinger et al., 2014) and as such, IL-36 $\gamma$ could be bolstering the inflammatory cascade in the FRT.

Poly (I:C), FSL-1, and flagellin treatments each resulted in unique IL-36 $\gamma$ expression and secretion patterns in our 3-D FRT EC models. TLR2, 3, 5, and 6 are the most abundantly expressed and functional in the FRT and our 3-D human FRT models (Herbst-Kralovetz et al., 2008; Hjelm et al., 2010; Radtke and Herbst-Kralovetz, 2012; Radtke et al., 2012). Flagellin targets TLR5, which activates the pro-inflammatory NF- $\kappa$ B pathway in parallel to apoptotic caspase cascades (Zeng et al., 2006).
FSL-1 signals through TLR2/6, which also leads to the proinflammatory NF- $\mathrm{B}$ pathway, but also triggers the MAPK pathway leading to possible apoptosis through MyD88 and caspase 8 (Aliprantis et al., 2000). Increased levels of IL-36r were detected in 3-D FRT EC cell culture supernatant following FSL-1 treatment, but not following flagellin treatment. The mechanism of secretion is unclear as IL-36 $\gamma$ lacks a conventional signal sequence (Towne et al., 2011), and further work must be performed to determine IL-36 $\gamma$ secretion mechanisms in FRT EC. Poly (I:C) triggers TLR3 in the endosome, activating inflammation through the NF- $\kappa$ B pathway. Poly (I:C) has also been shown to induce FRT EC pro-inflammatory cytokine secretion, recruiting immune cells that activate cellular defense 
mechanisms, limiting viral replication until an adaptive immune response is generated (Schaefer et al., 2005; Herbst-Kralovetz

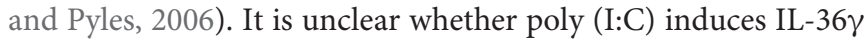
secretion via a signaling sequence or via cell death, but it is possible that IL-36 $\gamma$ acts as an alarmin, alerting surrounding cells of danger (Lian et al., 2012).

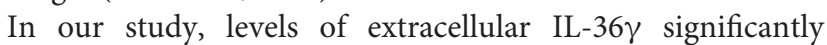
increased and intracellular IL-36 $\gamma$ decreased following high dose treatments with poly (I:C). In contrast, flagellin treatment in FRT EC resulted in increased intracellular IL-36 $\gamma$ protein with corresponding supernatants containing low levels of extracellular

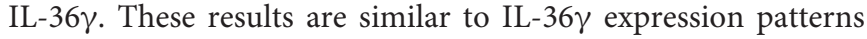
observed in a study by Lian et al. in keratinocytes (Lian et al., 2012). These microbial product-specific induction and secretion relationships suggest that IL-36 $\gamma$ influences TLR dependent cellular defense responses unique to different forms of microbial attack. Further studies are required, but our data suggest that IL$36 \gamma$ secretion may play a role in antimicrobial host defense and regulating tissue specific immune responses to infection in the FRT by amplifying the mucosal immune response.

IL-36 $\gamma$ activates the release of cytokines and chemokines from surrounding cells, leading to inflammatory host defense against invading pathogens. Prolonged inflammation in the FRT may also act as a warning sign of infection, indicating that IL-36 $\gamma$ may act as a marker for FRT disease or inflammation. A recent proteomics report demonstrated that cervicovaginal lavages collected from women with bacterial vaginosis exhibited elevated levels of IL-36 $\alpha$ and IL-36 receptor antagonist relative to controls, further supporting a role for IL-36 family members in the FRT (Borgdorff et al., 2015). Both 3-D vaginal and endocervical EC responded to rIL-36 $\gamma$ treatment by upregulating gene expression of IL-6, IL- 8 , IL- $1 \beta$, and TNF $\alpha$. Each of these immune mediators has been found to be elevated in human cervicovaginal lavages collected from women with STI (Trifonova et al., 2007; Kyongo et al., 2015), as well as in the cell lines used in our 3-D FRT EC cultures following STI exposure (HerbstKralovetz et al., 2008; Hjelm et al., 2010; Radtke and HerbstKralovetz, 2012; McGowin et al., 2013). However, preliminary studies have not shown significant changes in TLR expression following rIL-36 $\gamma$ treatment (data not shown). We found that treating the 3-D FRT EC with rIL-36 $\gamma$ induced expression of IL-36R and cellular IL-36 $\gamma$. A study by Friedrich et al. with keratinocytes defined this autocrine function as a self-amplifying loop involving IL-17 (Friedrich et al., 2014). IL-36 $\gamma$ has also been shown to induce CCL20, a Th17 cytokine, in lung fibroblasts due to asthma and COPD (Chustz et al., 2011) and in dermatoses

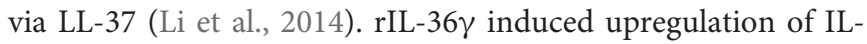
$36 \gamma$ and IL-36R mRNA as well as CCL20 mRNA and protein in 3-D FRT EC models suggesting the induction of an IL$36 \gamma$ amplification loop following TLR activation. The increased secretion of CCL20 and its impact on Th17 cell recruitment and activation may play a role in host defense against FRT insult and is a future area of investigation.

AMP are present in the FRT during homeostasis and production is increased following infection in the FRT, as detected in cervicovaginal lavages (Novak et al., 2007; Keller et al., 2012; Madan et al., 2012; Pellett Madan et al., 2015). AMP induction by IL-36 $\gamma$ has been observed in keratinocytes and bronchial ECs (Chustz et al., 2011; Lian et al., 2012; Li et al., 2014). We investigated a panel of AMP known to be expressed in the lower FRT (Yarbrough et al., 2015) for induction by rIL$36 \gamma$ exposure. Our data shows that each of these AMP (CCL20, HE4, SLPI, HBD-2, and HBD-4) were induced by treatment with rIL-36 $\gamma$, further promoting inflammation in FRT EC in a dosedependent fashion. CCL20, HBD-2, and HBD-4 upregulation was more robust in $3-\mathrm{D}$ vaginal $\mathrm{EC}$ relative to cervical EC. Following pathological insult, serine protease inhibitors HE4 and SLPI have an inverse relationship, for example in bacterial vaginosis, HE4 is elevated, whereas SLPI is decreased (Mitchell et al., 2008). Interestingly, rIL-36 $\gamma$ treatment induced HE4 and SLPI expression in 3-D FRT models, similar to IL-1 treatment (Bingle et al., 2006). Further investigation is needed to determine if AMP induction by IL-36 $\gamma$ enhances host defense or results in damaging inflammation.

In the FRT, IL-36 $\gamma$ may function as a key regulator of mucosal inflammation. This is the first study to report the induction and regulation of IL-36 $\gamma$, IL-36R, and related immune mediators in the human FRT following microbial product exposure. Both IL$36 \gamma$ and IL-36R were induced by rIL-36 $\gamma$ in a dose dependent fashion, as well as a number of AMPs, pro-inflammatory cytokines, and chemokines in the FRT. The IL-36 family has been associated with the pathogenesis of several inflammatory diseases. Our data suggest that IL-36 $\gamma$ could play a critical role in initiating, promoting and sustaining epithelial-mediated inflammation to microbial products in the FRT. As such, future work will be aimed at studying the role of the IL-36 family in the context of the FRT in terms of host response to vaginal microbiota, STI pathogens, and other reproductive disorders.

\section{AUTHOR CONTRIBUTIONS}

$\mathrm{MH}-\mathrm{K}$ contributed to the conception and design of the experiments. SW and AT acquired the data. SW, AT, and $\mathrm{MH}-\mathrm{K}$ all contributed to the analysis and interpretation of the data, drafting the manuscript and revising it critically for intellectual content and approve of the final version of the manuscript.

\section{FUNDING}

This work was supported by the National Institutes of Health and NIAID Grant 1R15AI113457-01A1 (to MH-K).

\section{ACKNOWLEDGMENT}

The authors would like to acknowledge Dr. Pawel Laniewski for critical review of the manuscript.

\section{SUPPLEMENTARY MATERIAL}

The Supplementary Material for this article can be found online at: http://journal.frontiersin.org/article/10.3389/fmicb.2016. 00955 


\section{REFERENCES}

Agrawal, T., Vats, V., Wallace, P. K., Salhan, S., and Mittal, A. (2008). Role of cervical dendritic cell subsets, co-stimulatory molecules, cytokine secretion profile and beta-estradiol in development of sequalae to Chlamydia trachomatis infection. Reprod. Biol. Endocrinol. 6:46. doi: 10.1186/1477-7827-6-46

Aliprantis, A. O., Yang, R. B., Weiss, D. S., Godowski, P., and Zychlinsky, A. (2000). The apoptotic signaling pathway activated by Toll-like receptor-2. EMBO J. 19, 3325-3336. doi: 10.1093/emboj/19.13.3325

Barrila, J., Radtke, A. L., Crabbe, A., Sarker, S. F., Herbst-Kralovetz, M. M., Ott, C. M., et al. (2010). Organotypic 3D cell culture models: using the rotating wall vessel to study host-pathogen interactions. Nat. Rev. Microbiol. 8, 791-801. doi: $10.1038 /$ nrmicro2423

Berglof, E., Andre, R., Renshaw, B. R., Allan, S. M., Lawrence, C. B., Rothwell, N. J., et al. (2003). IL-1Rrp2 expression and IL-1F9 (IL-1H1) actions in brain cells. J. Neuroimmunol. 139, 36-43. doi: 10.1016/S0165-5728(03)00130-9

Bingle, L., Cross, S. S., High, A. S., Wallace, W. A., Rassl, D., Yuan, G., et al. (2006). WFDC2 (HE4): a potential role in the innate immunity of the oral cavity and respiratory tract and the development of adenocarcinomas of the lung. Respir. Res. 7:61. doi: 10.1186/1465-9921-7-61

Borgdorff, H., Gautam, R., Armstrong, S. D., Xia, D., Ndayisaba, G. F., van Teijlingen, N. H., et al. (2015). Cervicovaginal microbiome dysbiosis is associated with proteome changes related to alterations of the cervicovaginal mucosal barrier. Mucosal Immunol. 9, 621-633. doi: 10.1038/mi.2015.86

Chustz, R. T., Nagarkar, D. R., Poposki, J. A., Favoreto, S. Jr., Avila, P. C., Schleimer, R. P., et al. (2011). Regulation and function of the IL-1 family cytokine IL-1F9 in human bronchial epithelial cells. Am. J. Respir. Cell Mol. Biol. 45, 145-153. doi: 10.1165/rcmb.2010-0075OC

Cuchacovich, R., Espinoza, C. G., Virk, Z., and Espinoza, L. R. (2008). Biologic therapy (TNF-alpha antagonists)-induced psoriasis: a cytokine imbalance between TNF-alpha and IFN-alpha? J. Clin. Rheumatol. 14, 353-356. doi: 10.1097/RHU.0b013e318190dd88

Doerflinger, S. Y., Throop, A. L., and Herbst-Kralovetz, M. M. (2014). Bacteria in the vaginal microbiome alter the innate immune response and barrier properties of the human vaginal epithelia in a species-specific manner. J. Infect. Dis. 209, 1989-1999. doi: 10.1093/infdis/jiu004

Drapkin, R., von Horsten, H. H., Lin, Y., Mok, S. C., Crum, C. P., Welch, W. R., et al. (2005). Human epididymis protein 4 (HE4) is a secreted glycoprotein that is overexpressed by serous and endometrioid ovarian carcinomas. Cancer Res. 65, 2162-2169. doi: 10.1158/0008-5472.CAN-04-3924

Dunn, E., Sims, J. E., Nicklin, M. J., and O’Neill, L. A. (2001). Annotating genes with potential roles in the immune system: six new members of the IL-1 family. Trends Immunol. 22, 533-536. doi: 10.1016/S1471-4906(01)02034-8

Friedrich, M., Tillack, C., Wollenberg, A., Schauber, J., and Brand, S. (2014). IL-36gamma sustains a proinflammatory self-amplifying loop with IL-17C in anti-TNF-induced psoriasiform skin lesions of patients with Crohn's disease. Inflamm. Bowel Dis. 20, 1891-1901. doi: 10.1097/MIB.0000000000000198

Gabay, C., and Towne, J. E. (2015). Regulation and function of interleukin36 cytokines in homeostasis and pathological conditions. J. Leukoc. Biol. 97, 645-652. doi: 10.1189/jlb.3RI1014-495R

Gresnigt, M. S., Rosler, B., Jacobs, C. W., Becker, K. L., Joosten, L. A., van der Meer, J. W., et al. (2013). The IL-36 receptor pathway regulates Aspergillus fumigatus-induced Th1 and Th17 responses. Eur. J. Immunol. 43, 416-426. doi: 10.1002/eji.201242711

Gresnigt, M. S., and van de Veerdonk, F. L. (2013). Biology of IL-36 cytokines and their role in disease. Semin. Immunol. 25, 458-465. doi: 10.1016/j.smim.2013.11.003

Herbst-Kralovetz, M. M., and Pyles, R. B. (2006). Quantification of poly(I:C)mediated protection against genital herpes simplex virus type 2 infection. J. Virol. 80, 9988-9997. doi: 10.1128/JVI.01099-06

Herbst-Kralovetz, M. M., Quayle, A. J., Ficarra, M., Greene, S., Rose, W. A. II, Chesson, R., et al. (2008). Quantification and comparison of toll-like receptor expression and responsiveness in primary and immortalized human female lower genital tract epithelia. Am. J. Reprod. Immunol. 59, 212-224. doi: 10.1111/j.1600-0897.2007.00566.x

Hjelm, B. E., Berta, A. N., Nickerson, C. A., Arntzen, C. J., and Herbst-Kralovetz, M. M. (2010). Development and characterization of a three-dimensional organotypic human vaginal epithelial cell model. Biol. Reprod. 82, 617-627. doi: 10.1095/biolreprod.109.080408
Horne, A. W., Stock, S. J., and King, A. E. (2008). Innate immunity and disorders of the female reproductive tract. Reproduction 135, 739-749. doi: 10.1530/REP07-0564

Jarvis, G. A., Li, J., and Swanson, K. V. (1999). Invasion of human mucosal epithelial cells by Neisseria gonorrhoeae upregulates expression of intercellular adhesion molecule 1 (ICAM-1). Infect. Immun. 67, 1149-1156.

Jensen, L. E. (2010). Targeting the IL-1 family members in skin inflammation. Curr. Opin. Investig. Drugs 11, 1211-1220.

Johnston, A., Xing, X., Guzman, A. M., Riblett, M., Loyd, C. M., Ward, N. L., et al (2011). IL-1F5, -F6, -F8, and -F9: a novel IL-1 family signaling system that is active in psoriasis and promotes keratinocyte antimicrobial peptide expression. J. Immunol. 186, 2613-2622. doi: 10.4049/jimmunol.1003162

Keller, M. J., Madan, R. P., Shust, G., Carpenter, C. A., Torres, N. M., Cho, S., et al. (2012). Changes in the soluble mucosal immune environment during genital herpes outbreaks. J. Acquir. Immune Defic. Syndr. 61, 194-202. doi: 10.1097/QAI.0b013e31826867ae

Krzyzowska, M., Baska, P., Orlowski, P., Zdanowski, R., Winnicka, A., Eriksson, K., et al. (2013). HSV-2 regulates monocyte inflammatory response via the Fas/FasL pathway. PLoS ONE 8:e70308. doi: 10.1371/journal.pone.0070308

Kumar, S., McDonnell, P. C., Lehr, R., Tierney, L., Tzimas, M. N., Griswold, D. E., et al. (2000). Identification and initial characterization of four novel members of the interleukin-1 family. J. Biol. Chem. 275, 10308-10314. doi: 10.1074/jbc.M000449200

Kyongo, J. K., Crucitti, T., Menten, J., Hardy, L., Cools, P., Michiels, J., et al. (2015). Cross-sectional analysis of selected genital tract immunological markers and molecular vaginal microbiota in sub-saharan African women, with relevance to HIV risk and prevention. Clin. Vaccine Immunol. 22, 526-538. doi: 10.1128/CVI.00762-14

Li, N., Yamasaki, K., Saito, R., Fukushi-Takahashi, S., Shimada-Omori, R. Asano, M., et al. (2014). Alarmin function of cathelicidin antimicrobial peptide LL37 through IL-36gamma induction in human epidermal keratinocytes. J. Immunol. 193, 5140-5148. doi: 10.4049/jimmunol.1302574

Lian, L. H., Milora, K. A., Manupipatpong, K. K., and Jensen, L. E. (2012). The double-stranded RNA analogue polyinosinic-polycytidylic acid induces keratinocyte pyroptosis and release of IL-36gamma. J. Invest. Dermatol. 132, 1346-1353. doi: 10.1038/jid.2011.482

Madan, R. P., Carpenter, C., Fiedler, T., Kalyoussef, S., McAndrew, T. C., Viswanathan, S., et al. (2012). Altered biomarkers of mucosal immunity and reduced vaginal Lactobacillus concentrations in sexually active female adolescents. PLoS ONE 7:e40415. doi: 10.1371/journal.pone.0040415

McGowin, C. L., Radtke, A. L., Abraham, K., Martin, D. H., and HerbstKralovetz, M. (2013). Mycoplasma genitalium infection activates cellular host defense and inflammation pathways in a 3-dimensional human endocervical epithelial cell model. J. Infect. Dis. 207, 1857-1868. doi: 10.1093/infdis/jit101

Medina-Contreras, O., Harusato, A., Nishio, H., Flannigan, K. L., Ngo, V., Leoni, G., et al. (2016). Cutting Edge: IL-36 receptor promotes resolution of intestinal damage. J. Immunol. 196, 34-38. doi: 10.4049/jimmunol.1501312

Mitchell, C. M., Balkus, J., Agnew, K. J., Cohn, S., Luque, A., Lawler, R., et al. (2008). Bacterial vaginosis, not HIV, is primarily responsible for increased vaginal concentrations of proinflammatory cytokines. AIDS Res. Hum. Retroviruses 24, 667-671. doi: 10.1089/aid.2008.0268

Mutamba, S., Allison, A., Mahida, Y., Barrow, P., and Foster, N. (2012). Expression of IL-1Rrp2 by human myelomonocytic cells is unique to DCs and facilitates DC maturation by IL-1F8 and IL-1F9. Eur. J. Immunol. 42, 607-617. doi: 10.1002/eji.201142035

Novak, R. M., Donoval, B. A., Graham, P. J., Boksa, L. A., Spear, G., Hershow, R. C., et al. (2007). Cervicovaginal levels of lactoferrin, secretory leukocyte protease inhibitor, and RANTES and the effects of coexisting vaginoses in human immunodeficiency virus (HIV)-seronegative women with a high risk of heterosexual acquisition of HIV infection. Clin. Vaccine Immunol. 14, 1102 1107. doi: 10.1128/CVI.00386-06

Pellett Madan, R., Masson, L., Tugetman, J., Werner, L., Grobler, A., Mlisana, K., et al. (2015). Innate antibacterial activity in female genital tract secretions is associated with increased risk of HIV acquisition. AIDS Res. Hum. Retroviruses 31, 1153-1159. doi: 10.1089/AID.2015.0011

Pudney, J., Quayle, A. J., and Anderson, D. J. (2005). Immunological microenvironments in the human vagina and cervix: mediators of cellular immunity are concentrated in the cervical transformation zone. Biol. Reprod. 73, 1253-1263. doi: 10.1095/biolreprod.105.043133 
Quayle, A. J. (2002). The innate and early immune response to pathogen challenge in the female genital tract and the pivotal role of epithelial cells. J. Reprod. Immunol. 57, 61-79. doi: 10.1016/S0165-0378(02)00019-0

Radtke, A. L., and Herbst-Kralovetz, M. M. (2012). Culturing and applications of rotating wall vessel bioreactor derived 3D epithelial cell models. J. Vis. Exp. 62:3868. doi: $10.3791 / 3868$

Radtke, A. L., Quayle, A. J., and Herbst-Kralovetz, M. M. (2012). Microbial products alter the expression of membrane-associated mucin and antimicrobial peptides in a three-dimensional human endocervical epithelial cell model. Biol. Reprod. 87:132. doi: 10.1095/biolreprod.112.103366

Schaefer, T. M., Fahey, J. V., Wright, J. A., and Wira, C. R. (2005). Innate immunity in the human female reproductive tract: antiviral response of uterine epithelial cells to the TLR3 agonist poly(I:C). J. Immunol. 174, 992-1002. doi: 10.4049/jimmunol.174.2.992

Segueni, N., Vigne, S., Palmer, G., Bourigault, M. L., Olleros, M. L., Vesin, D., et al. (2015). Limited contribution of IL-36 versus IL-1 and TNF pathways in host response to mycobacterial infection. PLoS ONE 10:e0126058. doi: 10.1371/journal.pone.0126058

Stordeur, P., Poulin, L. F., Craciun, L., Zhou, L., Schandene, L., de Lavareille, A., et al. (2002). Cytokine mRNA quantification by real-time PCR. J. Immunol. Methods 259, 55-64. doi: 10.1016/S0022-1759(01)00489-6

Towne, J. E., Garka, K. E., Renshaw, B. R., Virca, G. D., and Sims, J. E. (2004). Interleukin (IL)-1F6, IL-1F8, and IL-1F9 signal through IL-1Rrp2 and IL1RAcP to activate the pathway leading to NF-kappaB and MAPKs. J. Biol. Chem. 279, 13677-13688. doi: 10.1074/jbc.M400117200

Towne, J. E., Renshaw, B. R., Douangpanya, J., Lipsky, B. P., Shen, M., Gabel, C. A., et al. (2011). Interleukin-36 (IL-36) ligands require processing for full agonist (IL-36alpha, IL-36beta, and IL-36gamma) or antagonist (IL-36Ra) activity. J. Biol. Chem. 286, 42594-42602. doi: 10.1074/jbc.M111.267922

Towne, J. E., and Sims, J. E. (2012). IL-36 in psoriasis. Curr. Opin. Pharmacol. 12, 486-490. doi: 10.1016/j.coph.2012.02.009
Trifonova, R. T., Bajpai, M., Pasicznyk, J. M., Chandra, N., Doncel, G. F., and Fichorova, R. N. (2007). Biomarkers of leukocyte traffic and activation in the vaginal mucosa. Biomarkers 12, 608-622. doi: 10.1080/135475007016 00670

Vigne, S., Palmer, G., Lamacchia, C., Martin, P., Talabot-Ayer, D., Rodriguez, E., et al. (2011). IL-36R ligands are potent regulators of dendritic and T cells. Blood 118, 5813-5823. doi: 10.1182/blood-2011-05-356873

Vos, J. B., van Sterkenburg, M. A., Rabe, K. F., Schalkwijk, J., Hiemstra, P. S., and Datson, N. A. (2005). Transcriptional response of bronchial epithelial cells to Pseudomonas aeruginosa: identification of early mediators of host defense. Physiol. Genom. 21, 324-336. doi: 10.1152/physiolgenomics. .00289.2004

Yarbrough, V. L., Winkle, S., and Herbst-Kralovetz, M. M. (2015). Antimicrobial peptides in the female reproductive tract: a critical component of the mucosal immune barrier with physiological and clinical implications. Hum. Reprod. Update 21, 353-377. doi: 10.1093/humupd/dmu065

Zeng, H., Wu, H., Sloane, V., Jones, R., Yu, Y., Lin, P., et al. (2006). Flagellin/TLR5 responses in epithelia reveal intertwined activation of inflammatory and apoptotic pathways. Am. J. Physiol. Gastrointest. Liver Physiol. 290, G96-G108. doi: 10.1152/ajpgi.00273.2005

Conflict of Interest Statement: The authors declare that the research was conducted in the absence of any commercial or financial relationships that could be construed as a potential conflict of interest.

Copyright (c) 2016 Winkle, Throop and Herbst-Kralovetz. This is an open-access article distributed under the terms of the Creative Commons Attribution License (CC BY). The use, distribution or reproduction in other forums is permitted, provided the original author(s) or licensor are credited and that the original publication in this journal is cited, in accordance with accepted academic practice. No use, distribution or reproduction is permitted which does not comply with these terms. 